aggressive neoplasm with poor prognosis which might be of interest for the clinicians.

Case presentation We herein report a case of a 14-year-old girl suffering from cough and back pain for one week. Computerised tomography showed bilateral pleural effusions and mediastinal axillary lymph nodes. The specimen from pleural effusion showed a transudate character with no tuberculosis or no sign of malignancy. Because of increasing dyspnea, a chest tube was inserted and pleural and lung parenchyma biopsy was performed and no definite diagnosis was done. After two weeks, chest tube was drawn. 4 days later, the patient admitted to our emergency room with dyspnea and back pain. Because of increased pleural effusion, the patient was intubated immediately and was referred to paediatric intensive care unit. Detailed diagnostics tests showed anaemia, thrombocytopenia, hypoechoic lesions on spleen and liver, intraabdominal multiple lymph nodes, sclerotic lesions on vertebrae. A tru-cut biopsy was performed by interventional radiology and malignant infiltration was reported. Chemotherapy was initiated to the patient however, the patient's status was altered and died.

Conclusion We present a case of primary pulmonary NK cell lymphoma. The course of the disease was fulminant although the patient received aggressive chemotherapy and other symptomatic treatments. Our case who had difficulty in diagnosis may help to clinicians to identify other cases with NK cell lymphoma, their treatment and outcomes.

\section{PO-0272 EVALUATION OF PROPOFOL FOR SEDATION IN NEONATAL ENDOTRACHEAL INTUBATION}

${ }^{1} Z$ Merchaoui, ${ }^{1} \mathrm{~N}$ Le Saché, ${ }^{1} \mathrm{~L}$ Julé, ${ }^{2} \mathrm{E}$ Salvador, ${ }^{1} \mathrm{C}$ Magne, ${ }^{2} \mathrm{JL}$ Chabernaud, ${ }^{1} \mathrm{P}$ Tissières. ${ }^{1}$ Neonatal and Pediatric Intensive Care Unit, Assistance Publique-Hôpitaux de Paris (AP-HP) Paris South University Hospitals, Le Kremlin Bicêtre, France; ${ }^{2}$ SMUR Pédiatrique, Assistance Publique-Hôpitaux de Paris (AP-HP) Paris South University Hospitals, Clamart, France

\subsection{6/archdischild-2014-307384.926}

Background Propofol is increasingly used as a rapid and short acting induction agent. Concerns about cardiovascular side effects have limited its use in neonates. In our level III NICU and prehospital paediatric medical team, propofol is the first drug of choice for all intubations in hemodynamically stable newborns.

Aim To evaluate efficacy and tolerance of propofol in neonates. Methods Monocentric prospective observational study, conducted between June 2012 and March 2014 including neonates needing elective endotracheal intubation. Patients received a starting dose of $1 \mathrm{mg} / \mathrm{kg}$ of propofol. Additional doses of 0.5 $\mathrm{mg} / \mathrm{kg}$ were repeated until sufficient sedation was obtained. Haemodynamic parameters were recorded before, during and after propofol injection. The level of sedation, intubation conditions, and side effects were recorded.

Results Propofol was used in 89 intubations in 83 patients with a median gestational age of $31 \mathrm{wk}+5 \mathrm{~d}(25 \mathrm{wk}+6 \mathrm{~d}$ to $41 \mathrm{wk}$ $+3 \mathrm{~d}$ ), postnatal age was $4 \mathrm{~h}$ (17 $\mathrm{min}$ to 67 days), and weight was $1530 \mathrm{~g}(610-4820 \mathrm{~g})$. A propofol starting dose was sufficient in $34 \%$ of patients. A total dose of $2 \mathrm{mg} / \mathrm{kg}$ was efficient in the $73 \%$ of patients. Physicians were satisfied about the intubation conditions in $75 \%$. Short and moderate hypotension occurred in $32 \%$ of patients independently of doses and gestational ages ( $91 \%$ before $12 \mathrm{~h}$ of age). No patients required neither fluids nor vasopressor. The following side effects were also noted: apnea (35\%), bradycardia $(<10 \%)$.
Conclusion Propofol offered good intubation conditions without significant side effects. Doses needed to obtain sufficient sedation varied widely.

\section{PO-0273 COMMUNITY-ACQUIRED URINARY TRACT INFECTIONS (UTI) WITH EXTENDED-SPECTRUM BETA-LACTAMASE (ESBL) BACTERIA IN A FRENCH PAEDIATRIC EMERGENCY DEPARTMENT (PED)}

${ }^{1} \mathrm{M}$ Desmarest, ${ }^{2} \mathrm{P}$ Mariani, ${ }^{1} \mathrm{G}$ Galli-Gibertini, ${ }^{2} \mathrm{~S}$ Bonacorsi, ${ }^{1} \mathrm{JC}$ Mercier. ${ }^{1}$ Paediatric Emergency, Robert Debré Hospital, Paris, France; ${ }^{2}$ Bacteriology Lab (EA 3105 Université Paris Diderot), Robert Debré Hospital, Paris, France

\subsection{6/archdischild-2014-307384.927}

Background The prevalence of ESBL bacteria in communityacquired UTIs is increasing. This is of concern, since antibiotic therapy would be restricted to a few antibiotics, including carbapenems (in turn, the frequent use of penems leads to carbapenem-resistance), aminoglycosides, colimycin and fosfomycin.

Aims To describe the prevalence of ESBL among Gram-negative bacteria causing community-acquired UTIs managed in a tertiary care PED serving an active Department of paediatric urology.

Methods Retrospective study of all UTI episodes diagnosed between 1st January and 31th December, 2012. UTIs were retrieved by using the PED and Bacteriology databases.

Results $457(0.6 \%)$ community-acquired UTIs have been identified among 78,152 visits in the PED in 2012. 358 (78\%) were diagnosed as acute pyelonephritis based on clinical signs and elevated CRP and/or PCT, and 99 (21\%) as acute cystitis. Whereas no ESBL bacteria was identified among episodes of cystitis, 16 acute pyelonephritis cases were due to ESBL E.coli (i.e., $4.5 \%$ of all E.coli and $3.4 \%$ of all UTIs). 13/16 (81\%) UTIs occurred in children suffering urinary tract abnormalities. Moreover, one child with vesico-ureteral bilateral reflux had 3 distinct episodes of UTIs due to ESBL K.pneumoniae in 2012.

Conclusions The incidence of ESBL E. coli causing communityacquired UTIs remains low $(\sim 5 \%)$ in a tertiary hospital PED. This reassuring finding comforts the French UTI current recommendations of using as a first-line therapy iv ceftriaxone for 4 days followed by oral cefixime for 6 additional days. However, ESBL bacteria causing UTIs are favoured by urinary malformations, previous hospitalisations and prophylactic antibiotics.

\section{PO-0274 THE FIRST POLISH STUDY ON PARENT SATISFACTION IN PAEDIATRIC INTENSIVE CARE UNIT - THE EMPATHIC-30 POLAND STUDY}

${ }^{1} \mathrm{~K}$ Witulska, ${ }^{1} \mathrm{M}$ Migdal, ${ }^{1} \mathrm{E}$ Sulich, ${ }^{2} \mathrm{~J}$ Latour. ${ }^{1}$ Anaesthesiolgy and Intensive Care, Children's Memorial Health Institute, Warsaw, Poland; ' ${ }^{2}$ School of Nursing and Midwifery, Plymouth University, Plymouth, UK

\subsection{6/archdischild-2014-307384.928}

Aim The aim of the EMPATHIC-30 Poland study was to implement a validated parent satisfaction questionnaire.

Material and method The EMPATHIC-30 questionnaire was used with a written permission of author. The study has been performed at the 10 beds PICU. Inclusion criteria were all parents whose child was admitted to the PICU for at least $24 \mathrm{~h}$ and not died in this unit.

Results During 4 months 62 children (including 10 deaths) have been discharged from the PICU. There were 2 parents who refused to take part in the study, another 3 parents were not 